\title{
Needs Analysis in ESP Context: Saudi Engineering Students as a Case Study
}

\author{
Hashem Ahmed Alsamadani* \\ College of Education, Umm-Alqura University, P.O.Box 715 Makkah, Saudi Arabia \\ Correspond Author: Hashem Ahmed Alsamadani, E-mail: hmazawid@gmail.com
}

\section{ARTICLE INFO}

\section{Article history}

Received: August 23, 2017

Accepted: October 27, 2017

Published: December 30, 2017

Volume: 8 Issue: 6

Advance access: December 2017

Conflicts of interest: None

Funding: None

\section{Key words:}

Needs Analysis,

ESP,

Engineering Students,

English Skills,

Course Design

\begin{abstract}
Needs analysis can be a vital asset for teachers of English for specific purposes (ESP) to identify their learners' key requirements or needs and determine the areas in which they are lacking skills. Against this background, this study was undertaken during the academic year 2015-16 to define the English language needs of engineering students $(\mathrm{N}=200)$ majoring in civil engineering and industrial engineering. The data of this study was collected from different sources, including a classroom observation protocol, a questionnaire, and a semi-structured interview with both ESP and subject-matter teachers (SM) at Umm Al-Qura University. Results of the data analysis offered significant insights as to the teaching of ESP course. The study revealed that receptive skills (i.e., reading and listening) were mostly focused on in ESP classes. It has been also reported that writing and reading along with speaking skills were needed more than others. The data analysis helped to determine the most important language tasks in the context of engineering studies. Finally, a call was being made by both ESP and SM teachers to enhance the quality of the ESP course taught to engineering students by offering relevant suggestions. Based on these findings, the present study concluded with implications for course designers and recommendations for future studies.
\end{abstract}

\section{INTRODUCTION}

Seen as a data collection process (Nunan, 1988), needs analysis can be a vital asset for teachers of English for specific purposes (ESP) to identify learners' key requirements or needs and determine the skills they need to develop. Scholars have been debating on the focus of needs analysis. While Hutchinson and Waters (1987) consider learning needs as what the learner needs to do in order to learn, Benesch (2001: 72) perceives that needs are associated strictly with target situation demands. Some other researchers such as Taillefer, (2007) and Cowling, (2007) empirical evidence shows that the success of teaching and learning process in ESP depends much on needs analysis. It is clear thus that needs analysis can help learners adapt to the new learning system when their teachers recognize their needs of the learning process (Carkin, 2005; Chamot, 2007). One obvious advantage of needs analysis is that, by identifying them learners in general, needs analysis will identify the weaknesses and strengths of the skills that they may use in potential business or academic contexts. Therefore, the current study comes to add to the bulk of research on ESP Needs analysis. It can be considered a pragmatic and objective attempt to help ESP teachers Saudi Arabia to identify the best methods of teaching that are truly relevant to their learners.

\section{Research Problem and Rationale}

Although engineering students at higher education are argued to have their own needs, there has been little empirical investigation at the Saudi local context. Therefore, teaching English for engineering purposes is far from satisfactory in terms of customizing ESP courses by using the real needs of learners or the language situation at the workplace as the input to feed ESP courses. One implication of this is that when the specific language needs are not defined based on language use, students may end up being disappointed with the language proficiency level that they achieve once they join the work place. Another implication is that the effort of English teachers would lack focus if the language needs are not identified in terms of language use

A closer scrutiny of the learning situation at the engineering colleges at Umm Al-Qura University (in Al-Lith, and Al-qunfudah) reflects the need for engineering students to have a good level of proficiency in English since they deal with a large number of courses whose jargons are in English. Further, engineering is deemed among the most salient fields in which English is used extensively (Mudraya, 2006). Hence, this study, based on an authentic analysis of learners' present situation needs and target situation ones, aims to provide empirical data about the different needs of engineering students and the uses of English in the engineering field 
which, in return, can be used as an input to feed the larger structure of the local ESP context in higher education.

\section{Defining Needs Analysis}

It is difficult to find a consensus over the definition of needs analysis among ESP researchers. This can be explained by the seemingly problematic combination of two essentially subjective terms: "needs" and "analysis". While Hutchinson and Waters (1987) define needs as necessities, wants and lacks, Brindley (1989: 56) describe it as "the gap between what the learners' actual needs are and what should be taught to them." Therefore, it can be said that needs are what learners will be required to do with a foreign language in a target situation, and how learners might best master the target language during the period of training (West, 1994: 1). Analysis is essentially seen as the exploration process of communicative tasks, that is, what the learners need to do with the target language (Al-Otibi, 1994).

\section{Approaches to Needs Analysis}

There have been various approaches to needs analysis. The most common approaches include deficiency analysis, sociolinguistic model, learning-centered approach, target situation analysis (TSA), and present situation analysis (PSA).

\section{Deficiency Analysis}

Deficiency analysis is defined by West (1994) as a type of needs analysis designed to take account of learners' present needs/wants as well as the requirements of the target situation. West (1994) claimed that deficiency analysis included two central components: an inventory of potential target needs expressed in terms of activities, and a scale that is used to set the priority that should be given to each activity. For example, if a group of engineering students were to visit the United Kingdom, their host institution might give them a list of the activities most frequently needed by the field of engineering, and request that they rank the order of their importance to them. The major drawback of this type of needs analysis is that it can differ significantly from one student to another. In other words, one student may say that writing a report is of paramount importance while another might think that reading an academic article ranks most important.

One advantage of the approach of deficiency analysis is that it laid the basis for the use of the questionnaire method to determine learners' actual needs. Several researchers (Shaw, 1982; Bheiss, 1988) capitalized on the contribution of such an approach to needs analysis and conducted their studies by using different scales in their questionnaires to identify the most important activities for their participants. For example, Shaw (1982) asks his subjects to establish whether or not each potential need is an actual need, and then to present the level of difficulty experienced when performing each activity on a none/some/a lot scale. Most needs analysts (Anderson, 1980) have agreed that this approach attempts to investigate learners' future and present needs, which could be done by target situation analysis (TSA) and present situation analysis (PSA).

\section{Sociolinguistic Model}

Developed by Munby (1978), the sociolinguistic model is considered to be the first structured, detailed and most influential model used to identify the learners' needs, that is, the content of purpose-specific language programs. In this model, Munby (1978) puts the learner's target linguistic requirements at the heart of the ESP course. For instance, they constitute the basis for the course content and materials selection. In fact, the ultimate goal of the language course is to enable the learner to reach the "target communicative competence", which stands for the learner's ability to use the language communicatively in a real situation. Target communicative competence is characterized mainly by two criteria. While the first criterion indicates the learners' required level with reference to grammar, vocabulary and pronunciation, the second one refers to discourse and the context-related use of language. The communicative competence covers three levels of competence. The first level is grammatical which concerns the usage of the target language. The second level is sociolinguistic relating to the appropriate use of language in specific contexts. The third level is strategic referring to the capability to compensate for communication breakdowns.

This model presents some problems. First of all, it is directed more at the learner rather than at his/her needs. For example, learner's voice is not taken into account (West, 1994). Second, having developed everything in theoretical issue, the model can hardly be used in practice because it is inflexible, complex and time-consuming (West, 1994).

\section{Learning-Centered Approach}

Hutchinson and Waters (1987) have developed a learning-centered approach in view of designing a model that can easily analyze students' needs from the onset up to the target situation. Important in this systematic approach is that learners give much care to the learning process as a focus of the analysis rather than the knowledge they want to possess at the end of the classes. Target needs, as defined by Hutchinson and Waters (1987: 54), refer to "what the learner needs to do in the target situation." Such needs fall into three categories: necessities, lacks and wants. While necessities focus on what students have to know in order to be able to perform their responsibilities, lacks explain what people do not know "the gaps between what the learner knows and the necessities" (Hutchinson \& Waters, 1987: 56). As for wants, they are about "what the learners think they need" (Nation, 2000: 2).

Using Hutchinson and Waters' (1987) learning-centered approach is argued to offer many advantages. For instance, it can ensure a constant systematic assessment of students' needs with the help of such data collection instruments as interviews, surveys, questionnaires, and observations. Another feature of this approach concerns the use of authentic materials as a way to encourage students to cope with the original texts. Within this approach, Hutchinson and Waters (1987) recommend that needs analysis be checked constantly. They 
also stress the use of multiple methods of data collection to deal with the complexity of target needs.

\section{Needs Analysis for the Present Study}

Needs analysis for the present study considers two complementary approaches but will focus more on TSA than on PSA. These approaches are argued to be appropriate in the field of ESP (Blue, 1991; Dudley-Evans \& St John, 1998; Jordan, 1997; West, 1994, 1997) and have been endorsed by previous needs analysts. They have been chosen in view of all the drawbacks of each of the other approaches discussed above. PSA is about students' level of language and language use and what the students want to develop form TSA. Within this study, PSA is associated with TSA, and they will be carried out together. TSA is not adequate to determine the needs of the targeted students in English without considering their PSA. Therefore, taken together, TSA and PSA may explain which method(s) should be used in order to provide an adequate course design for engineering students at Umm Al-Qura University.

\section{Research Questions}

The present study was designed to answer the following research questions:

1- What is the English language proficiency of Saudi engineering ?

2- What are the language skills and activities much emphasized in ESP classes for engineering students ?

3- What English language skills do ESP and SM teachers perceive as the most important for engineering students in their workplace?

4- How do teachers perceive ESP course at Engineering colleges?

\section{RESEARCH DESIGN}

\section{Participants and Context}

Participants in the present study were ESP and subject-matter teachers $(\mathrm{N}=25$; age mean $=42)$ and second-year engineering students majoring in industrial engineering and civil engineering at Umm Al-Qura University (Al-Lith, and Al-Qunfudah) $(N=200$; age mean $=22)$. The sample was screened based on a convenience sampling system which gives the chance for both students and teachers to take part in this study. The targeted students were exposed to intensive course of English language at their first year of university career. This indicates that they were likely to be more aware of their needs.

The selection of ESP and SM teacher was grounded on the fact that they naturally had direct contact with their students and that they could provide useful information about their students' needs for English. They were likely to know their students' needs better than anyone else. They could give incisive and insightful feedback for course designers to define the goals and specific objectives of any suggested course.
Within the frame of this investigation, a systematic control of variables related to heterogeneity of the subjects was not feasible. It was not possible, for example, to control socio-economic variables. The common independent variable here is that they all are affiliates to the a college of Engineering at Umm Al-Qura University.

\section{Instrumentation and Data Collection}

To achieve triangulation and thereby reach valid results about the needs analysis of English language of engineering students, the current study used three different yet interrelated types of instruments: a classroom observation protocol, a structured questionnaire and a semi-structured interview protocol.

\section{Classroom Observation Protocol}

The design of classroom observation protocol (see Appendix A) was informed by research design of studies on needs analysis (Javid, 2011). This protocol took a time-sampling format whereby relevant classroom activities carried out by both students and teachers were recorded every minute in an ongoing manner. These activities were Student Reading Time (SRT), Student Listening Time (SLT), Student Writing Time (SWT), Teacher Speaking Time (TST), Student Speaking Time (SST) and Arabic Speaking Time (AST) both for the teachers and the students.

\section{Structured Questionnaire}

Based on the observation protocol results and Basturkmen's (1998) insights, a structured questionnaire comprising 26 items was developed (See Appendix B). The first section of the questionnaire gathered personal information about the subjects. The second section elicited their level of competence in English language proficiency based on a five-likert scale: 1. Excellent, 2. Very good, 3. Good, 4. Fair, and 5. Poor. In the third section, the targeted students were asked fourpoint Likert-scale questions as to their PSN and TSN. As far as the questionnaire design and layout were concerned, the optimal length of all questionnaires was three to four pages and each did not exceed a twenty-minute completion limit. Further, special attention was paid to their layouts in terms of fonts, spacing, and paper quality. Oppenheim (1992) argues that the professional quality of the layout can give a good impression about the questionnaire, which in turn affects the quality of the responses.

\section{Semi-Structured Interview Protocol}

The third tool was a semi-open ended interview protocol for SM and ESP teachers. Teachers were asked seven open-ended questions and two closed ended ones to discover the present situation needs (PSN) and target situation needs (TSN) of the subjects (see Appendix 3). The interview was used to support and/or explain the results obtained from the questionnaire. The interview open-ended questions covered the following points: (i) general background information 
regarding the interviewees' age, gender, and subject being taught; (ii) teachers' perception regarding the importance of English for engineering students; (iii) the most important skills that students need to carry out their studies; (iv) teachers' perception regarding the teaching of field-specifi terminology, (v) and teachers' comments and suggestions as to the improvement of the quality of ESP course.

All the interviews were audio-recorded, transcribed and translated if needed by the researcher. The transcription of the interview data was based on Gumperz and Berenz's (1993) convention system for transcribing conversational discourse. To verify the authenticity of the transcripts, the transcribed data were cross-checked with two teachers of English who were familiar with the study. Then, the interview transcripts were thematically coded in a systematic way "to reduce a complex, messy, context-laden and quantification resistant reality to a matrix of numbers" (Orwin, 1994: 140). Inter-coder reliability accounted for $90 \%$. The conflicts were solved through discussions between coders.

\section{RESULTS AND DISCUSSION}

This section presents and discusses the results of the study. Part one presents the quantitative analysis of the first two research instruments, namely, classroom observation protocol and structured questionnaire. Within this part, we deal with three research questions regarding language skills and activities mostly focused on in ESP classes, students' perception of their proficiency in English language skills and students' linguistic needs at the TS.

Part two is about the qualitative analysis of the third research instrument used. Within this part, we present results about the importance of English for engineering students as perceived by teachers, the most salient skills that students need, the teaching of field-specifi terminology and teachers' comments and suggestion for a practical ESP course at the engineering colleges of Umm Al-Qura University.

\section{Quantitative Analysis}

Language skills and activities mostly focused on in ESP classes at the engineering college of Al-Qunfudha.

As Figure 1 shows, the different language skills and classroom activities were found to be as important with more or less slight differences. What was so exciting was that receptive skills were identified to receive much focus in the ESP classes for the engineering students. Indeed, reading activities took 110 minutes, that is, $27 \%$ of the time allocated to classroom tasks, followed by listening skills with $23 \%$. Speaking activities were given $20 \%$ of the whole time. The most surprising finding was that writing activities were the least performed with $3 \%$ of the whole time given to classroom activities, that is, 13 minutes only. This indicates that teachers were concerned with developing receptive skills and sub-skills to the neglect of the productive ones. This conclusion can be supported by the type of classroom interactions which was marked by the dominance of teacher talk ( $20 \%$ of the classroom activities time). Student-student interactions took only $18 \%$ of the whole time of classroom activities or interactions. Worthy of note was that student talk (especially poor achievers) was featured by the use their native language, Arabic (9\%). They use such to elicit teachers' explanation of some new concepts or synonyms.

Overall, the results of the first question reflected that ESP classes are taught in a traditional way where the classroom is teacher-dominated and not learner-centered. Another crucial point was that writing skill, despite its importance, still receives less focus in the ESP teaching at higher education. The ESP classroom reality at the engineering college and the less emphasis given to productive skills could be explained by the proficiency level of the targeted engineering students. The next part deals with students' self-rating of their proficiency in English language skills.

Students' perception of their proficiency in English language skills

As far as students' proficiency in English language skills was concerned, there was a slight difference in the targeted subjects' self-ratings, as shown in the following table.

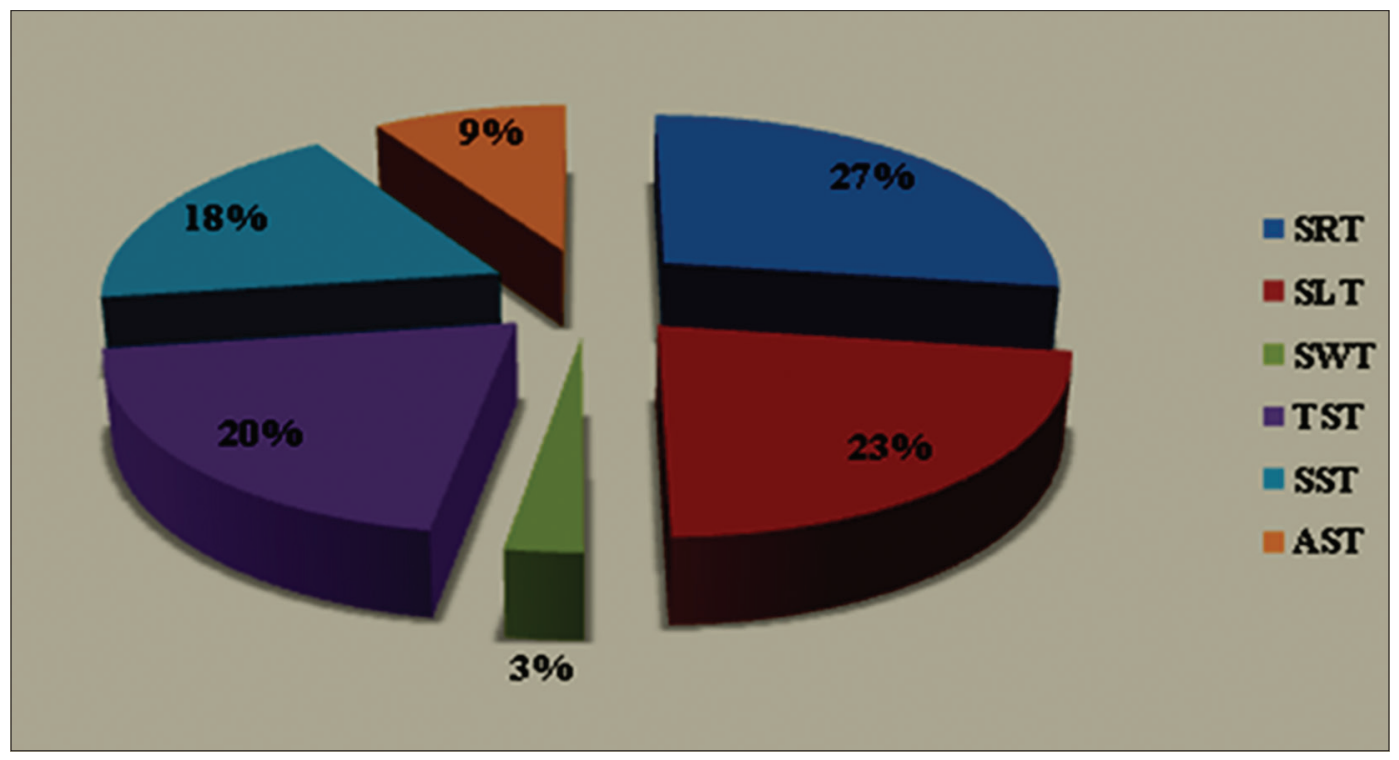

Figure 1. Distribution of language skills and activities mostly focused on in ESP classes 
Table 1 shows reading was ranked first $(\mathrm{M}=3.11$; $\mathrm{SD}=1.08)$. Listening was ranked the second skill at which the targeted students sound proficient, with a mean value of 2.58 and a SD value of 1.09. Crucial was that engineering students perceived themselves as less proficient in both speaking $(\mathrm{M}=2.54$. $\mathrm{SD}=1.19)$ and writing $(\mathrm{M}=2.26$; $\mathrm{SD}=1.04)$ skills.

What transpired from the above results was that the targeted students tend to develop the skills on which much emphasis is given in classroom. That is why, productive skills lagged behind receptive skills. The implication of this is that engineering students are likely to encounter communication problems in their potential workplace or when conducting research, for they lack much practice in and outside the classroom. These variations in students' English language skills proficiency could be accounted for by the teachers' perception of the importance of English skills to their students' studies or careers.

Students' perceived English language needs for carrying out their engineering studies

The last section of the students' questionnaire was concerned with thoroughly capturing subjects' perceived English language needs for effectively carrying out their engi-

Table 1. Students' perceptions of their proficiency in English language skills

\begin{tabular}{lcc}
\hline English Language Skill & Mean & SD \\
\hline Reading & 3.11 & 1.08 \\
Listening & 2.58 & 1.09 \\
Speaking & 2.54 & 1.19 \\
Writing & 2.26 & 1.04 \\
\hline
\end{tabular}

Table 2. Importance of English skills and components for effectively carrying out studies as perceived by students

\begin{tabular}{lllc}
\hline $\mathbf{N}^{\circ}$ & $\begin{array}{l}\text { Importance of English language } \\
\text { skills }\end{array}$ & Mean & SD \\
\hline 1 & $\begin{array}{l}\text { How important is listening skill for your } \\
\text { engineering studies at your college? }\end{array}$ & 1.76 & 0.81 \\
2 & $\begin{array}{l}\text { How important is speaking skill for your } \\
\text { engineering studies at your college? }\end{array}$ & 2.03 & 0.96 \\
3 & $\begin{array}{l}\text { How important is reading skill for your } \\
\text { engineering studies at your college? }\end{array}$ & 2.48 & 0.91 \\
4 & $\begin{array}{l}\text { How important is writing skill for your } \\
\text { engineering studies at your college? }\end{array}$ & 3.73 & 0.56 \\
5 & $\begin{array}{l}\text { How important is grammar for your } \\
\text { engineering studies at your college? }\end{array}$ & 2.03 & 0.96 \\
\hline
\end{tabular}

neering studies. The researcher got 200 questionnaires filled in. Table 2 below gives an account of the subjects' responses

As Table 2 shows, most engineering students rated the four English skills as relatively important. Writing was ranked as the most important among the skills where the mean was $(M=3.73)$, followed by reading skill $(\mathrm{M}=2.48$ and $\mathrm{SD}=0.96)$, then speaking skill and grammar $(M=2.03$ and $\mathrm{SD}=0.96)$. Listening skill ranked as somehow the least important with a mean value of 1.76 and a SD value of 0.81 . Results of the above table revealed that there was a lack of much emphasis on productive skills among engineering students, hence the need to work on developing such by either modifying the teaching techniques or course content.

\section{Students' Linguistic Needs at the TS}

Importance of listening sub-skills as perceived by engineering students

Analysis of the items 10 to 13 which investigated subjects' responses about important listening tasks showed various rankings, as illustrated in the following table.

Table 3 shows that 'following question/answer sessions' $(\mathrm{M}=1.74$ and $\mathrm{SD}=0.74)$ was the most listening task performed by students in ESP classes, followed by 'understanding instructions' $(\mathrm{M}=1.49$ and $\mathrm{SD}=0.69)$ and 'understanding power point presentations' respectively. Although means of listening activities were high, the ESP course seems to not handle different listening genres, which could result in a lack of interaction and problems in speaking.

Importance of speaking sub-skills as perceived by engineering students

The next 5 questions (14-18) were about the importance of speaking sub-skills as perceived by students. Analysis of students' ratings showed a slight variation in the rankings of such sub-skills.

As shown in Table 4 above, it was found that 'giving oral presentations' $(\mathrm{M}=1.83$ and $\mathrm{SD}=0.81)$ and 'answering questions' $(\mathrm{M}=1.50$ and $\mathrm{SD}=0.66)$ were perceived as the most important sub-skills of speaking. Lagged behind were the sub-skills of 'interacting with specialists', 'participating in classroom discussions' and 'asking questions' with no significant difference in their mean values. Considering the results of the speaking subskills at large, it can be concluded that students expressed an urgent need to develop interactional skills of communication.

Importance of reading sub-skills as perceived by engineering students

As far as reading tasks were concerned, high mean value of 2.38 was assigned to 'reading instructions for assignments'

Table 3. Importance of listening sub-skills as perceived by engineering students

\begin{tabular}{llrr}
\hline Listening skill & & Mean & SD \\
\hline & a- How important is listening to lectures? & 1.22 & 0.51 \\
Listening & b- How important is instructions understanding? & 1.49 & 0.69 \\
sub-skills & c- How important is following question/answer sessions? & 1.74 & 0.74 \\
& d- How important is understanding of power point presentations? & 1.46 & 0.71 \\
\hline
\end{tabular}


followed by classroom reading tasks, that is, 'reading handouts given by teachers' and 'reading field-related textbooks'. The lowest mean value (1.25) was calculated for only "reading articles in journals", as shown in Table 5 below.

According to the results represented in Table 5, it can be concluded that reading skills were considered important. This might be due to the methods of teaching used in classroom which focus much on reading skills. It can also be accounted for by its importance in conducting further research. Indeed, reading skills are routinely used in reviewing previous studies on a given research topic.

Importance of writing sub-skills as perceived by engineering students

Analysis of the last four items which investigated subjects' responses about important writing tasks showed various rankings, as illustrated in the following table.

'Writing field-specifi reports' was ranked as the most important writing sub-skill students need with mean value of 1.91 and SD value of 0.85 . 'Writing for class quizzes and exams' was ranked the second with mean value of 1.81 and SD value of 0.79 . "Writing assignment and homework" $(\mathrm{M}=1.66$ and $\mathrm{SD}=0.85)$ and "taking notes during lectures" $(\mathrm{M}=1.26$ and $\mathrm{SD}=0.55)$ were identified the least important sub-skills or tasks on this ranking. The different ranking values can imply that writing skill mainly focused on exams or assignments. Students seem to rarely work on developing the skill of writing for reports, which accounts for its top ranking as an urgent linguistic need.

Comparatively considering the descriptive statistics about the different English skills and sub-skills needed in ESP classes in Table 2 through Table 6, it can be concluded that engineering students needed English primarily for professional purposes at the TS (giving oral presentations, reading articles and writing specific field-specifi reports, etc) and then for academic purposes (exams, note taking, classroom participation, etc). The results revealed the need for exposure to an integrated skills approach. However, due to time constraints of any given ESP course, it seems difficult to prioritize the practice provided in each skill.

\section{Qualitative Analysis}

Qualitative analysis of data included all the results elicited from the questions of the semi-structured interview protocol. From the large amount of raw data, interpretation was conducted only on those potentially meaningful to the study. The qualitative data were presented and discussed in such a way as to reinforce and/or compare the results obtained in the quantitative data.

\section{Interview of Targeted Teachers}

\section{Importance of English for engineering students}

Question one sought their response about how important they thought English was for engineering students to carry out their content-subject studies at their college or perform well at workplace. All subjects strongly agreed that it was of vital importance and the following factors have been mentioned in this regard.

a. Their medium of research is English.

b. They need it to read their field-specifi textbooks which are most of the time written in English.

Table 4. Importance of speaking sub-skills as perceived by engineering students

\begin{tabular}{llrr}
\hline Speaking skill & & Mean & SD \\
\hline & a- How important is asking questions? & 1.37 & 0.54 \\
& b- How important is participating in classroom discussions? & 1.39 & 0.60 \\
Speaking & c- How important is answering questions? & 1.50 & 0.66 \\
sub-skills & d- How important is giving oral presentations? & 1.83 & 0.81 \\
& e- How important is interacting with specialists in your field of study? & 1.40 & 0.62 \\
\hline
\end{tabular}

Table 5. Importance of reading sub-skills as perceived by engineering students

\begin{tabular}{llcc}
\hline Reading skill & & Mean & SD \\
\hline \multirow{3}{*}{ Reading } & a- How important is reading articles in journals? & 1.25 & 0.47 \\
sub-skills & b- How important is reading instructions for assignments? & 2.38 & 0.79 \\
& c- How important is reading handouts given by teachers? & 1.60 & 0.69 \\
& d- How important is reading fiel -related textbooks? & 1.60 & 0.69 \\
\hline
\end{tabular}

Table 6. Importance of writing sub-skills as perceived by engineering students

\begin{tabular}{llcc}
\hline Writing skill & & Mean & SD \\
\hline \multirow{3}{*}{ Writing } & a- How important is taking notes during lectures? & 1.26 & 0.55 \\
sub-skills & b- How important is writing for class quizzes and exams? & 1.81 & 0.79 \\
& c- How important is writing assignment and homework? & 1.66 & 0.82 \\
& d- How important is writing fiel -specific reports & 1.91 & 0.85 \\
\hline
\end{tabular}


c. They need to read a lot of reference material in English if they intend to conduct further research and studies.

d. They need it to interact with their non-Arab teachers or researchers.

e. They need it to interact with professionals in their field

f. They need it to attend certain engineering seminars, workshops and conferences.

g. They need proficiency in English to perform better in their different job requirements.

Teachers' perception regarding the most important language skill for their students

Question two elicited the targeted teachers' perception about the most important language skill for their students to accomplish their engineering studies or to perform well at their potential workplace. Table 7 below gives an account of the distribution of the following four skills.

As Table 7 shows, according to $60 \%$ of the targeted teachers, the most important English skill needed for students was reading $(\mathrm{M}=3.2$ and $\mathrm{SD}=1.47)$. Listening skill was ranked as the second important skill for engineering students by $40 \%$ of the teachers with a mean value of 2.7 and a SD value of .95 . With regard to speaking skill, $40 \%$ of the teachers identified it as the third skill of great importance with a mean value of 2.3 and a SD value of .95 . With regard to writing skill, subjects' responses showed rather more variation when they were asked to rate its importance. Indeed, a good majority of respondents $(40 \%)$ identified it as very important for students' studies and future job requirements.

The statistics given in the table above indicates that the four English skills seem to play an important role in the engineering field. This field is also hailed as an international industry which often involves a range of inter-cultural encounters. The language of this industry is quite clearly English in an international context as well as in research, but it is also the language of meeting needs and of providing high levels of service, to name but a few.

Teachers' perception regarding the teaching of field-specific terminology

Question three in the interview protocol elicited teacher's perception regarding the teaching of engineering terminology in ESP classes. $60 \%$ of the targeted teachers strongly recommended that engineering terminology should be included in English syllabus whereas $40 \%$ considered it not a strong necessity. Rather, they recommended that pronunciation should be emphasized in particular.

All the faculty members unanimously reported that the students need reading skills to read relevant reference ma-

Table 7. Teachers' ratings of the importance of English skills for engineering students

\begin{tabular}{lccc}
\hline $\begin{array}{l}\text { English } \\
\text { Language skills }\end{array}$ & Mean & Median & $\begin{array}{c}\text { Standard } \\
\text { Deviation (SD) }\end{array}$ \\
\hline Speaking & 2.3 & 2 & 0.95 \\
Listening & 2.7 & 3 & 0.95 \\
Reading & 3.2 & 3 & 1.47 \\
Writing & 2.4 & 2 & 0.84 \\
\hline
\end{tabular}

terial from different sources. Speaking and listening were reported other important skills in this regard.

\section{Comments and Suggestions for a Practical ESP Course at Engineering Colleges}

All the interviewees were asked to give comments about the status quo of ESP learning/teaching at the engineering colleges in order to improve it. On a general level, ESP teachers provided comments and suggestions but SM teachers could not express their opinions in understandable English; some used poor English, some used Arabic, and some others mixed Arabic dialect with English. Using poor English or code-switching between Arabic and English gives a clue that their English proficiency was low. Regardless of the quality of English they used, they provided comments on how ESP course could be improved. The immediate task was to synthesize all the answers in such a way as to reveal possible patterns, yet without misrepresenting the data. This procedure was adopted to get a key word analysis, generating categories from the statements made by the respondents. This resulted in such categories as "what should be included in ESP course", "syllabus design", etc. Such categories were then grouped together according to whether they were referred to as language needs, learning needs or engineering-related needs.

To begin with, ESP teachers thought that the ESP course taught to engineering students seems irrelevant to either their potential research or workplace since it focused more on reading than writing or speaking skills. This supports the results in Figure 1 and Table 1 above. They also argued that the English course was introduced in non-supportive teaching conditions and there was no link between the ESP course and subject-matter courses. In this regard, they suggested that the ESP course should have been designed and prepared by both the ESP and SM teachers. However, in reality, ESP teachers and SM teachers seem to have never met to discuss and share ideas on teaching English for the engineering students. Besides, it was recommended that more time should be assigned to English course during the first two years

As for SM teachers, based on their experience they stated that engineering students could face many difficulties in English. They believed that ESP teachers should not allow students to use other language than English to help them develop their speaking skills. They also suggested that more time should be allocated to GE course as well as ESP classes. This was similar to the ESP teachers' suggestion. In addition, they thought that students should have been provided with supplementary materials that can enhance the ESP program. Important was that they recommended providing ESP teachers with a specialized training that will help them make the ESP course successful and productive. Indeed, in evaluating the progress of ESP as a component of English language teaching (ELT), Swales (1985: 214) contends that "one of the most constraining factors to this progress is the lack of specialized teacher-training." This situation applied even more emphatically at higher education where very little attention, if any, has been given to ESP teacher training thus far. 
On the whole, all these interviewees' comments corresponded to what Dudley-Evans and St John (1998) consider as effective ways of learning needs of students, namely, the skills they might need to develop as well as the lacks that should be dealt with. The given comments also showed that an urgent policy-intervention should be undertaken. Put differently, English teachers, administrators and syllabus designers have to join efforts and find solutions that meet the students' needs including language needs, learning needs and field-specific needs, among many other

\section{DISCUSSION}

The results generated by the three instruments: classroom observation, close-ended questionnaire, and semi-structured interview protocol identifi $d$ that reading skill was the most important skills for engineering students. This finding echoes the conclusions of many studies (Labassi, 2009; Rais, 2007) that ESP courses focuses mainly on reading skills. Writing skills, where students were reported to have low level probably out of the scant attention given to it, were perceived by students as one of the most important targeted needs. This finding contradicts that of Basturkmen's (1998) study where he reported that writing was not very important for ESP students. The questionnaire data indicated that listening was the least important skill for students whereas teachers perceived it as the second important skill as shown in the interview results. The implication of this was that students seemed to under-estimate the importance of different language skills without considering their specific academic or professional needs. Indeed, it has been reported that 'the questionnaire might have unreal answers, vague responses that require clarification (Rizk, 2006: 97). Hence, this fact should be taken into account when designing an ESP course for engineering students.

The variations in the results about the importance of language skills can be accounted for by the type of the ESP course which tends to be language-based where much focus was put on grammar and vocabulary. Such a course cannot be responsive to all students' needs. Students may at best attain a 'textbook' type of knowledge of ESP or English, but may not be able to use English in the professional world.

On the basis of the results, a number of recommendations were offered to upgrade the ESP course for engineering students. A highly structured ESP course for engineering, integrating academic skills with subject or field-specifi skills, derived directly from the learners' discipline should be framed. Such a course, if based on a pervasive and comprehensive 'needs analysis', is expected to facilitate the process of mastering both academic and subject-matter specific aspects of the target language as well as motivate students to become actively involved in the process of learning. That is, a needs-based syllabus is expected to accommodate for ESP needs in terms of skills at the macro and micro levels. However, worthy of note is that NA is not a process administered once and for all at the beginning of the course; rather, it should be an on-going process repeated during the life of the ESP program.

\section{REFERENCES}

Al-Otibi, A, M. (1994). Identifying the English Communication Needs of Kuwaiti Student Soldiers at the Military Institute in Kuwait. Unpublished Ph.D thesis. UK: Cardiff University College.

Anderson, J.R. (1980). Cognitive Psychology and its Implications. San Francisco: W.H.

Freeman.

Basturkmen, H. (1998). A Needs Analysis Project at Kuwait University. English Teaching Forum, 36(4). Retrieved September 10, 2007, from the World Wide Web: http:// exchanges.state.gov/forum/vols/vol36/no4/p2.htm.

Benesch, S. (2001). Critical English for Academic Purposes: Theory, Politics, and Practice. Mahwah/New Jersey: Lawrence ErlbaumAssociates, Publishers.

Bheiss, M. (1988). English for Nursing Purposes: the English LanguageNeeds at the Nursing School of Al-MakassedHospital (Jerusalem). Unpublished MED TESOL Dissertation. UK: University of Manchester.

Blue, G, (1991). Language Learning within Academic Constraints. In P. Adams, B. Heaton \& P. Howarth (Eds.), Socio-cultural Issues in English for Academic Purposes (pp. 100-116). London: Macmillan.

Brindley, G. (1989). The Role of Needs Analysis in Adult ESL Programme Design. In R. Johnson (Ed.), The Second Language Curriculum (pp. 43-78). Cambridge: Cambridge University Press.

Chamot, A. (2007). Accelerating Academic Achievement of English LanguageLearners: A Synthesis of Five Evaluations of the CALLA Model. In J. Cummins\& C. Davison (Eds.), International Handbook of English LanguageTeaching (pp. 85-104). LLC: Springer Sciences and Business Media.

Carkin, S. (2005). English for Academic Purposes. In E. Hinkel (Ed.), Handbook of Research in Second LanguageTeaching and Learning (pp. 85-98). Mahwah, NJ: Lawrence Erlbaum.

Cowling, D. (2007). Needs Analysis: Planning a Syllabus for a Series of Intensive Workplace Courses at a Leading Japanese Company. English for SpecificPurposes, 26, 426-442.

Dudley-Evans, T. \& St John, M. (1998). Developments in English for SpecificPurposes: A Multi- DisciplinaryApproach. Cambridge: Cambridge University Press.

Gumperz, J. J., \&Berenz, N. B. (1993). TranscribingConversationalExchanges. In J. A. Edwards \& D. L. Martin (Eds.), Talking Data: Transcription and Coding in Discourse Research (pp. 91-121). Hillsdale/NJ: Lawrence Erlbaum.

Hutchinson, T., \& Waters, A. (1987). English for SpecificPu poses: A Learning CentredApproach. Cambridge: Cambridge University Press.

Javid, C. Z. (2011). EMP Needs of MedicalUndergraduates in a Saudi Context. Kashmir Journal of Language Research, 14, 89-110.

Jordan, R. R. (1997). English for Academic Purposes: A Guide and Resource Book for Teachers. Cambridge: Cambridge University Press. 
Labassi, T. (2009). Reading Titles of Empirical Research Papers. Reading Matrix, 9, 166- 174.

Mudraya, O. (2006). Engineering English: A Lexical FrequencyInstructional Mode. English for SpecificPurpo es, 25, 235-256.

Munby, J. (1978). Communicative Syllabus Design: A Sociolinguistic Model for Defining the Content of Purpose-SpecificLanguage Programmes. Cambridge: Cambridge University Press.

Nation, P. (2000). Designing and Improving a Language Course. Forum, 38, 2.

Nuan, D. (1988). The Learner-Centred Curriculum. Cambridge: Cambridge University Press.

Oppenheim, A. (1992). Questionnaire Design, Interviewing and Attitude Measurement. London: Pinter.

Orwin, R.G. (1994). Evaluating Coding Decisions. In H. Cooper \& L.V. Hedges (Eds.), The Handbook of Research Synthesis (pp. 139-162). New York: Russell Sage Foundation.

Rais, N. (2007). Needsanalysis for a Business English Course at the Institut Supérieur de Gestion (Unpublished master's thesis). Institut Supérieur des Langues de Tunis.
Reimer, M. J. (2002). English and Communication Skills for the Global Engineer. Global J. of Engng. Educ, 6, 91-100.

Shaw, P. (1982). Ad hoc Needs Analysis. LanguageTeaching, 27, 1-19.

Swales, J. (1985). Episodes in ESP. Oxford: Pergamon Institute of English.

Taillefer, G. (2007). The ProfessionalLanguageNeeds of EconomicGraduates: Assessment and Perception for French Context. English for SpecificPurposes, 26, $135-155$

Rizk, S. (2006). ESP for Business Students: A New Approach. In: M. S. Lahlu, and A. Richardson (Eds.), English for SpecificPurposes in the Arab World (pp. 95108), TESOL Arabia. Dubai.

West, R. (1994). Needs Analysis in LanguageTeaching. LanguageTeaching, 27, 15-49.

West, R. (1997). Needs Analysis: A State of the Art. In R. Howard \& G. Brown (Eds.), Teacher Education for LSP (pp. 24-95). Colchester: MultilingualMatters.

\section{APPENDIX A}

Classroom Observation Protocol

1. Subject:

2. Date:

3. Time:

4. Name of the Teacher:

5. Time for different activities:

\begin{tabular}{|r|r|r|r|r|r|}
\hline $\mathbf{0}$ & Activity & Time (minutes) & No & Activity & Time (minutes) \\
\hline 1 & SRT & & 4 & TST & \\
\hline 2 & SLT & 5 & SST & \\
\hline 3 & SWT & 6 & F/AST & \\
\hline
\end{tabular}

\section{Any other observations:}

\section{APPENDIX B}

\section{Students' structured Questionnaire}

\section{I- Background}

Name: ....

Age:.

Field of study

Email:..... 
* What level of proficiency do you think you have in the following language skills or components?

$1=$ Excellent $2=$ very good $3=\operatorname{good} \quad 4=$ fair $5=$ poor

1. Listening

2. Speaking

3. Reading

4. Writing

\section{II- Language Needs}

* Rank the following according to their importance. Circle the most appropriate choice.

$1=$ very important $\quad 2=$ important $\quad 3=$ not important $\quad 4=$ not applicable

5. How important is listening skill?

6. How important is speaking skill?

7. How important is reading skill?

8. How important is writing skill?

9. How important is grammar?

$\begin{array}{llll}1 & 2 & 3 & 4\end{array}$ 4
4

$\begin{array}{llll}1 & 2 & 3 & 4\end{array}$

$\begin{array}{llll}1 & 2 & 3 & 4\end{array}$

$\begin{array}{llll}1 & 2 & 3 & 4 \\ 1 & 2 & 3 & 4\end{array}$

$\begin{array}{llll}1 & 2 & 3 & 4\end{array}$

\section{Listening}

10. Listening to lectures

11. Understanding instructions

12. Following question/answer sessions

13. Understanding power point presentations

$\begin{array}{llll}1 & 2 & 3 & 4 \\ 1 & 2 & 3 & 4 \\ 1 & 2 & 3 & 4 \\ 1 & 2 & 3 & 4\end{array}$

\section{Speaking}

14. Asking questions

15. Participating in discussions

16. Answering the questions

17. Giving oral presentations

18. Interacting with specialists in your field of stud

$\begin{array}{llll}1 & 2 & 3 & 4 \\ 1 & 2 & 3 & 4 \\ 1 & 2 & 3 & 4 \\ 1 & 2 & 3 & 4 \\ 1 & 2 & 3 & 4\end{array}$

\section{Reading}

19. Field -related textbooks

20. Articles in journals

21. Handouts given by teachers

22. Instructions for assignments

$\begin{array}{llll}1 & 2 & 3 & 4 \\ 1 & 2 & 3 & 4 \\ 1 & 2 & 3 & 4 \\ 1 & 2 & 3 & 4\end{array}$

\section{Writing}

23. Taking notes in lectures

24. Class quizzes and exams

25. Assignments and homework

26. Field-specific report

$\begin{array}{llll}1 & 2 & 3 & 4 \\ 1 & 2 & 3 & 4 \\ 1 & 2 & 3 & 4 \\ 1 & 2 & 3 & 4\end{array}$

\section{APPENDIX C}

\section{Teachers' Semi-structured Interview Protocol}

\section{Part I}

\section{Background Information}
1. Name:
2. Gender:
3. Age:.
4. What subject(s) do you teach? 


\section{Part II}

1. To what extent do you think English is important for engineering students to carry out their studies or to perform well at the workplace?

2. What language skill do you perceive engineering students at need the most to carry out their engineering studies effectively?

3. Do engineering students need to be taught field-specific terminology in English course Why?

4. How do you evaluate the teaching of English course? What can you suggest to improve the quality of ESP teaching and learning as well? 